DOI 10.37882/2223-2982.2021.10-2.20

\title{
ПРОЕКТНАЯ МЕТОДИКА КАК СРЕДСТВО ВОСПИТАНИЯ ТОЛЕРАНТНОСТИ И УЛУЧШЕНИЯ КОММУНИКАТИВНЫХ НАВЫКОВ СТУДЕНТОВ ПРИ ОБУЧЕНИИ ИНОСТРАННОМУ
} Я3bIKy

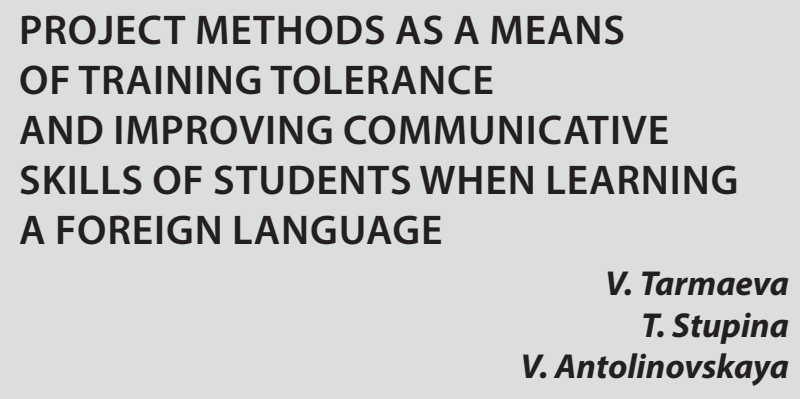

\section{Tarmaeva \\ T. Stupina \\ V. Antolinovskaya}

Summary: The article is devoted to the research of the possibilities and prospects of using project activities in tolerance development among university students. The pedagogical model of tolerance development is analyzed. The potential of the project methods in language education is considered. Their effectiveness in listening, speaking, reading, translation and writing skills development is highlighted, as well as productive nature in the formation of empathy and positive interpersonal interaction of project participants.

Keywords: tolerance, project methods, educational technologies, communication, foreign language.

\author{
Тармаева Виктория Ивановна \\ Д.филол.н., профессор, Сибирский федеральный \\ университет (Красноярск) \\ vtarmaeva@mail.ru \\ Ступина Татьяна Владимировна \\ К.культурологии, дочент, Сибирский федеральный \\ университет (Красноярск) \\ stupina_tv@mail.ru \\ Антолиновская Вера Михайловна \\ Старший преподаватель, Сибирский федеральный \\ университет (Красноярск) \\ antolinv@mail.ru
}

Аннотация: Статья посвящена исследованию возможностей и перспектив использования проектной деятельности в воспитании толерантности у студентов вузов. Анализируется педагогическая модель воспитания толерантности. Рассматривается потенциал проектной методики в языковом образовании. Отмечается ее эффективность в развитии навыков аудирования, говорения, чтения, перевода и письма, а также продуктивный характер в формировании эмпатии и позитивного межличностного взаимодействия участников проекта.

Ключевые слова: толерантность, проектная методика, образовательные технологии, коммуникация, иностранный язык.
$\mathrm{B}$ оспитание толерантного отношения к окружающим людям и развитие межкультурной компетенции являются важнейшими стратегическими задачами современного образования. Проблема формирования навыков толерантного общения, взаимопонимания и согласия в различных коммуникативных ситуациях вызывает несомненный исследовательский интерес, в том числе теоретиков образования. Психолого-педагогические положения воспитания толерантности отражены в научных трудах А.Г. Асмолова, В.В. Глебкина, Л.П. Ильченко, 3.Х. Магомадовой, Е.А. Некрасовой, Л.И. Рюмшиной, Л.И. Семиной, Г.У. Солдатовой, О.Д. Шаровой, Н.С. Юлиной. В данных работах воспитание толерантности рассматривается через призму приобщения обучающихся к жизни в мире людей, носителей разнообразных идей и представлений.

Проблема воспитания толерантности студентов на основе и средствами межкультурной коммуникации в современной педагогике остается малоизученной. В частности, воспитательный потенциал иностранного языка исследован недостаточно полно. Актуальность и научная неразработанность данного вопроса обозначили проблематику исследования - выявить возможности и перспективы языкового образования в воспитании толерантности студентов вузов. Целью научной работы стала апробация модели воспитания толерантности студентов неязыковых специальностей на основе выполнения ими проектных заданий на занятиях по иностранному языку.

Теоретической основой исследования послужили работы И.В. Авакумова, М.С. Каган, А. Ленгле, С.Л. Франк и др., определяющие приоритет ценностей в процессе воспитания; работы И.А. Макаровой, В.И. Мурашова, А.Д. Новиковой и др., подчеркивающие значимость духовно-ориентированного подхода в вопросах воспитания; работы Д. Адамса, Ю.С. Давыдова, П. Николсона, Б.Э. Риэрдон, Г.У. Солдатовой, М. Уолцера и др., обосновывающие потребность и роль современной цивилизации в толерантном взаимодействии; работы теоретиков коммуникативно-деятельностного подхода в обучении 
иностранному языку, а именно, исследования И.Л. Бим, Н.Д. Гальсковой, Р.П. Мильруда и Е.И. Пассова.

Проведенное исследование также послужило проверкой гипотезы о связи улучшения коммуникативных навыков на иностранном языке с систематическим применением проектной методики, инновационных форм и инструментов взаимодействия студентов в ходе образовательного процесса.

Вопросы использования проектной деятельности в контексте языкового образования отражены в трудах отечественных и зарубежных ученых: И.Л. Бим, Г.Д. Брауна, В.В. Гузеева, И.А. Зимней, Д. Камфорта, Э. Коллингса, М.В. Крупениной, Е.С. Полат, Т.Е. Сахаровой, М.А. Филлипса, Д. Фрид-Бута, Т. Хатчинсона, Д.В. Чернилевского, В.Н. Шульгина, С.Т. Шацкого и др.

С 1980-х годов проектная технология находит активное применение в процессе обучения иностранным языкам, обеспечивая продуктивный характер учебной деятельности, активизируя творческие и коммуникативные умения обучающихся, воплощая идею интегрированного обучения, формируя не только языковое сознание, но и глобальное мышление, которое способствует развитию личности $[3 ; 5]$.

При использовании проектной технологии происходит изменение не только формы организации образовательного процесса, но и роли его участников. Активной стороной в познавательной деятельности становится обучающийся/студент. Преподаватель выступает организатором общения, помощником и/или консультантом. Совместная работа студента и преподавателя определяется как общение на равных, поскольку именно такое взаимодействие, происходящее в атмосфере взаимопонимания и сотрудничества, выступает необходимым условием реализации проектного подхода, по мнению Г.Д. Брауна [2].

Как справедливо отмечает М.А. Филлипс, актуальность и популярность проектной методики можно объяснить тем, что при работе с данной технологией задействованы все виды мотивов, в частности, перспективно-побуждающие, моральные, мотивы общения и эмоционального удовлетворения [4]. Кроме того, проект модернизирует устоявшиеся подходы, предлагает нестандартные решения, в определенных условиях мобилизует творческое мышление, формирует способность «транспортировать» знания, умения и навыки из привычной ситуации в новую, повышает языковую компетенцию и мотивацию студентов к изучению иностранных языков [1].

В условиях высшей школы повышение эффективно- сти обучения на занятиях по иностранному языку, учитывая ограниченные временные рамки курса (как правило, 2-4 семестра), возможно, с нашей точки зрения, применяя инновационные подходы, методики и технологии, в частности, активно внедряя видео, аудио и мультипроекты в образовательный процесс.

\section{Методология исследования}

В основу проведенного эксперимента была положена гипотеза, в соответствии с которой предполагалось, что воспитание толерантности у студентов возможно посредством применения проектной методики, которая значительно эффективнее обеспечивает необходимый уровень общей и профессиональной коммуникативной компетенции.

Необходимо было также подтвердить предположение о том, что систематическое применение проектной методики способствует расширению словарного запаса обучающихся, формирует критическое мышление, развивает навыки аудирования, чтения и перевода, умения формулировать мысли, идеи и предложения, доказывать свою точку зрения, другими словами, интенсифицирует развитие коммуникативных навыков на иностранном языке.

Апробация проектного подхода осуществлялась в группах первого и второго курсов направлений бакалавриата и магистратуры Института филологии и языковой коммуникации и Политехнического института Сибирского федерального университета. В течение четырех семестров обучения после каждого пройденного модуля студенты выполняли контрольные индивидуальные и групповые проектные задания на иностранном, а именно, английском языке, включая сбор и оформление, обсуждение и представление информации по определенной, выбранной из предлагаемого перечня теме в виде творческой работы (создание видеороликов, лонгридов, документальных фильмов, написание аналитических и новостных статей, прохождение веб-квеста), активно применяя средства сетевой коллаборации, электронные, дистанционные образовательные технологии.

Непрямой метод обучения иностранному языку был реализован в три этапа: организационно-подготовительный, технологический, рефлексивный (обобщающерефлексивный). Каждый этап представлял заданную последовательность действий.

Организационно-подготовительный этап затрагивал теоретические аспекты проектной технологии, подразумевал обсуждение специфики, вариантов и процедуры выполнения проекта (содержание, объем, элементы, требования к оформлению, многообразие и сложность 
профессионального творчества), включал знакомство студентов с особенностями защиты и оценки, ранними проектными заданиями коллег. На данном этапе была представлена ресурсная база и возможные варианты используемых сетевых сервисов.

На следующем (технологическом) этапе осуществлялся выбор проблемы для проекта, его тип, структура и дизайн. Авторы проекта определяли задачи и состав участников. Происходила пошаговая реализация проекта, проводился контроль индивидуальных и/или групповых проектных заданий на стадии промежуточного анализа, а также проводились консультации с преподавателем, обсуждались проблемные аспекты.

Рефлексивный этап предполагал непосредственно защиту/представление проектной работы (презентации) с мультимедийным сопровождением, ответы на вопросы и оппонирование. Кроме того, в рамках данного этапа производилась комплексная оценка и осмысление проектного задания, его результатов, включая самооценку участников, оценку со стороны слушателей/наблюдателей, оценку преподавателя, подводились итоги мероприятия и давались комментарии, происходил поиск методов и средств улучшения используемой проектной технологии. В завершении данного этапа было проведено анкетирование. Для заполнения предлагался лист самооценки автора проекта, который включал несколько вопросов: «Что мною сделано особенно удачно?», «Что нового я узнал(а) за время работы?», «Какие языковые навыки и умения я усовершенствовал(а) при работе над проектом (аудирование, чтение, перевод, письмо, говорение)?», «Где в дальнейшем я намерен(а) использовать собранные материалы?», «Помогли ли мне методические рекомендации преподавателя и консультации с ним?», «Удовлетворен(а) ли я результатами своей работы над проектом?», «Какие профессионально-направленные навыки и умения вы усовершенствовали (приобрели) при работе над проектом?», «Будет ли полезен опыт проведенной проектной работы в дальнейшем в вашей профессиональной деятельности?».

В соответствии с основной задачей исследования, направленной на выявление у студентов вузов четырех показателей: национальные стереотипы; социальная дистанция по отношению к представителям другой культуры, расы, вероисповедания; отношение к вариативным проявлениям «инаковости»; наличие в понятийном аппарате концепта «толерантность»/«интолерантность», в нашем эксперименте применялись разнообразные методы диагностики: наблюдение, беседа, анкетирование, построение шкалы социальной дистанции Э. Богардуса.

Формирование понимания толерантности как отношения, необходимого для взаимодействия осущест- влялось посредством организации работы над проектом, нацеленным на создание лонгрида, посвященного проблеме толерантности в современном мире, а также при прохождении этапов веб-квеста, создании документального фильма и в процессе написания аналитических статей на данную тему, новостных сообщений, повествующих о различных проявлениях толерантного и интолерантного отношения в существующих обстоятельствах.

В процессе работы над проектами студенты пользовались информационно-коммуникационными интернет-технологиями, различными мессенджерами, блогами, вики, виртуальными досками, Google формами, средствами синхронной и асинхронной коммуникации, которые вовлекали студентов в ситуации реальной межкультурной коммуникации. Работа над проектами была посвящена традициям и обычаям, истории, литературе, географии, экономике различных государств, а также культуре коренных малочисленных народов России. Данная активность стимулировала участников к открытому, живому диалогу, используя ресурсы английского языка в общении с представителями иностранных государств.

\section{Анализ результатов}

Ответы на вопросы «Что мною сделано особенно удачно?», «Что нового я узнал(а) за время работы над проектом?» свидетельствуют о продуктивном характере учебной проектной деятельности, способствующей реализации личного творческого потенциала студентов, воздействующей на накопление индивидуального опыта в области освоения и использования на практике иностранного языка.

Защита проектов, по мнению 43 студентов (из 45 из числа всех участников), способствовала созданию праздничного настроя. Два студента (из 45) отметили данное событие как «важное мероприятие». Отсутствие отрицательной оценки за проект, возможность самому оценить свою работу, похвалить и проявить себя, желание попробовать свои силы и применить знания английского языка, по мнению студентов, создавало положительную мотивацию к выполнению работы и созданию атмосферы успеха.

На вопросы анкеты («Помогли ли мне методические рекомендации преподавателя и консультации с ним?», «Удовлетворен(а) ли я результатами своей работы над проектом?», «Будет ли полезен опыт проведенной проектной работы в дальнейшем в вашей профессиональной деятельности?») все студенты дали положительные ответы. Данная реакция демонстрирует эффективность и действенность проектной технологии, активизирующей формирование коммуникативных умений и про- 
фессиональных навыков обучающихся. Двадцать один студент отметил, что проектная работа стала «пробой профессиональных возможностей на иностранном языке». Таким образом, студенты, специализирующиеся в радиожурналистике, представили аудио файлы с интервью; студенты, интересующиеся телевизионной журналистикой, продемонстрировали документальные фильмы; большинство студентов выбрали создание мультипроекта (лонгрида) в качестве проектной работы. Четверо студентов написали, что «они еще не решили, будут ли заниматься профессиональной журналистикой, но опыт проектной работы им крайне интересен и полезен для совершенствования знаний английского языка».

Семнадцать студентов, которые работали над аудио проектом, признали, что навыки аудирования и говорения были ими улучшены. Как оказалось, студенты, снимавшие видео (13 студентов), усовершенствовали навыки говорения, чтения, перевода и письма. Авторы лонгридов (15 студентов) уточнили, что навыки чтения и письма на английском языке стали у них лучше. Результаты тестов и контрольных заданий на аудирование, чтение, перевод, письмо и говорение в конце семестров оказались выше предыдущих, когда проектная технология не внедрялась активно в учебный процесс.

Проектная, проблемно-ориентированная технология с поэтапным выполнением учебных заданий (в частности, коллаборативное задание «веб-квест») кроме интенсивного языкового погружения также способствовала, по мнению 20 студентов магистратуры инженерного профиля, самоорганизации, эмпатии, позитивному межличностному взаимодействию, мобильности и гибкости, успешности в решении поставленных задач. Десять студентов отметили расширение общекультурных знаний, обогащение собственной картины мира. Семь студентов были готовы нести ответственность за поддержание партнёрских и доверительных отношений внутри коллектива/проектной группы.

Ответы на вопросы «Какие профессионально-направленные навыки и умения вы усовершенствовали (приобрели) при работе над проектом?», «Где в дальнейшем я намерен(а) использовать собранные материалы?» показали, что профессионально-приобретенные умения и навыки (и собранные материалы) определялись соответственно специализации будущих журналистов и инженеров (в радиожурналистике, телевизионной журналистике, интернет журналистике, стандартизации, управлении качеством, надзорной и инспекционной деятельности в сфере труда).

Результаты проведенных тестов на знание вокабу- ляра у студентов, занимавшихся проектной деятельностью, по сравнению с теми, кто в проекте не участвовал, были схожие (равное количество студентов, написавших на «отлично», «хорошо», «удовлетворительно»). Различие проявилось в том, что среди студентов, не вовлеченных в проектную деятельность, оказались те (2 студента), которые не смогли успешно справиться с тестом на знание слов по изучаемым темам. Студенты, прошедшие проектную форму обучения, написали тест успешно.

Положительная динамика в области сокращения социальной дистанции по отношению к различным народам наблюдалась у студентов по результатам заключительной диагностики проведенного исследования. Если на начальном этапе 4/5 студентов полагали, что стараются быть толерантными, не показывая свое неприятие по отношению к другим людям, то на заключительном этапе - 65,5\% студентов признались, что ощущают толерантные чувства и находятся на уровне ценностно-смысловой толерантности.

\section{Выводы}

Результаты эксперимента показали, что часть гипотезы о том, что наиболее эффективные методы обучения студентов возможны на интегративной основе в рамках профессионально-направленного обучения, можно считать подтвержденной полностью.

С целью выявления «остаточных знаний» через три месяца был предъявлен этим же студентам тест на знание лексики. Результаты у студентов, занимавшихся проектом, а также обучавшихся вне проектной деятельности, оказались одинаковыми. Эти результаты не могут служить подтверждением того, что проектная методика может рассматриваться эффективной формой закрепления словарного запаса в долговременной памяти по сравнению с традиционными методами обучения.

Другой вывод относительно возможностей проектной методики представляется положительным. Мы можем утверждать, что использование проектной методики и средств сетевой коллабориции способствует повышению уровня толерантности студентов, приводит к сокращению социальной дистанции, позитивному взаимодействию и обогащению, поиску содержательных компромиссов, активизирует переход толерантности в ценностно-смысловую структуру личности студента. Толерантность рассматривается ими не исключительно в аспекте терпимого отношения к «иному», к тому, что студент не можем понять, принять или объяснить. Толерантность осознается как принцип коммуникативного взаимодействия. 


\section{ЛИТЕРАТУРА}

1. Тармаева В.И. 0 применении проектной методики в преподавании русского языка как иностранного / В.И. Тармаева // Правоохранительные органы: теория и практика. - 2019. - № 2. - С. 200-201.

2. Brown H. Douglas. Principles of Language Learning and Teaching. London: Pearson Education, 2007. - $423 \mathrm{p}$.

3. Hutchinson T. Introduction to Project Work. Oxford: Oxford University Press, 1996. - $400 \mathrm{p}$.

4. Phillips M.A. Consideration of Two Approaches to Providing Materials for ESP. London: British Council, 1978. - p.

5. Widdowson H.G. Learning Purposes and Language Use. Oxford: Oxford University Press, 1983. - 122 p.

\section{(с) Тармаева Виктория Ивановна (vtarmaeva@mail.ru), Ступина Татьяна Владимировна (stupina_tv@mail.ru),}

Антолиновская Вера Михайловна (antolinv@mail.ru).

Журнал «Современная наука: актуальные проблемы теории и практики»

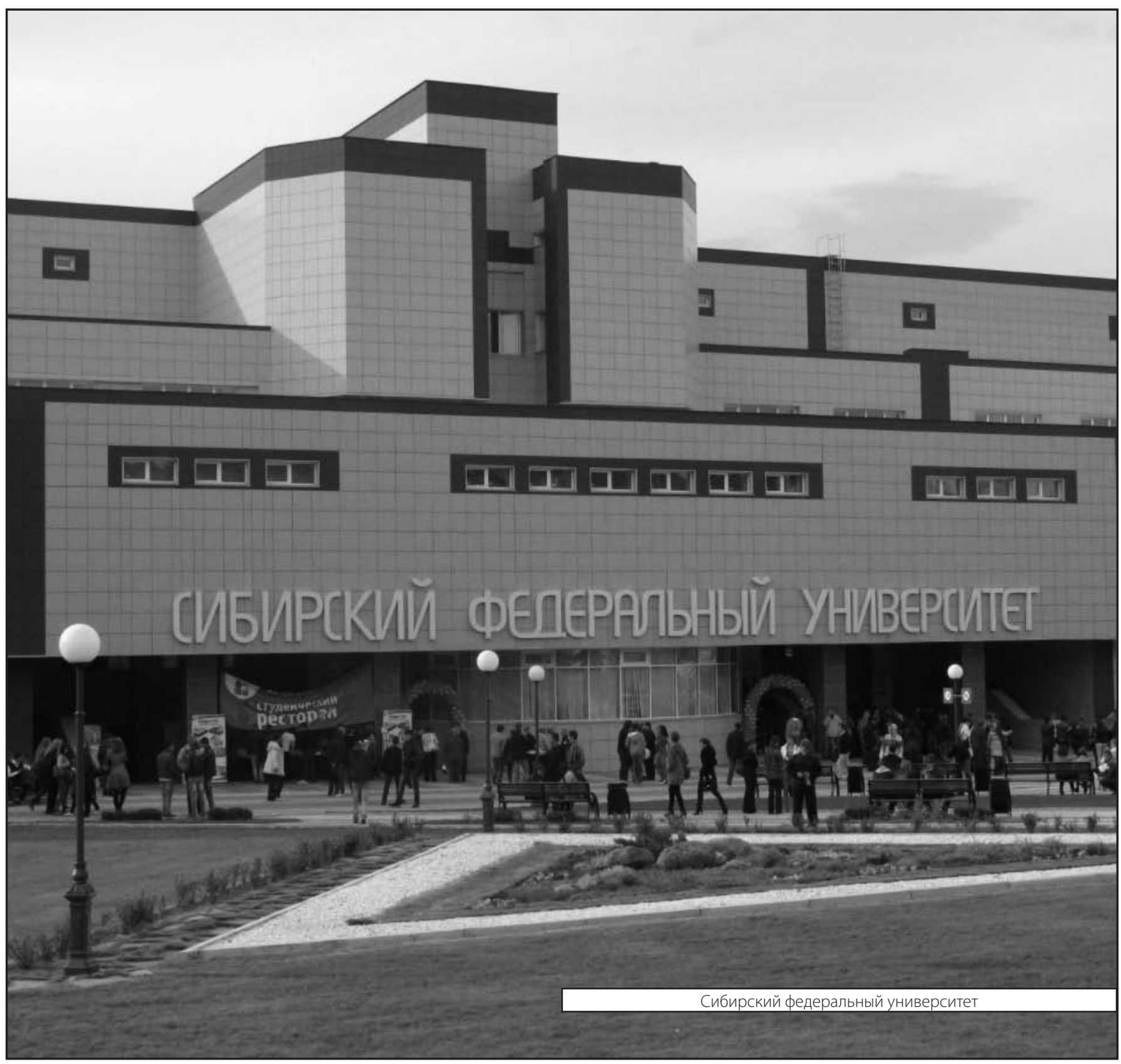

